\title{
Solidaritas Sosial dalam Ekstrakulikuler Sispala di SMA Pembangunan Laboratorium UNP
}

\author{
Sefrilina Sefrilina ${ }^{1}$, Mira Hasti Hasmira ${ }^{2}$ \\ 1,2 UniversitasNegeri Padang
}

Email: sefri.liina@gmail.com, mirahasti@fis.unp.ac.id

\begin{abstract}
Abstrak
Penelitian ini bertujuan untuk melihat solidaritas dalam ekstrakulikuler sispala di SMA Pembangunan Laboratorium UNP. Teori yang digunakan dalam penelitian ini adalah teori solidaritas sosial yang dikemukakan oleh Emile Durkheim. Metode yang digunakan dalam penelitian ini ialah pendekatan kualitatif dengan tipe penelitian deskriptif. Data diperoleh dengan cara observasi, wawancara dan dokumentasi. Lalu data yang didapat dianalisis menggunakan teknik dari Miles dan Huberman. Hasil dari penelitian ini ditemukan adanya 3 bentuk solidaritas dalam ekstrakulikuler sispala, yaitu 1. Solidaritas antara sesame anggota dalam ekstrakulikuler sispala, bentuk dari solidaritas sosialnya adalah seringnya kegiatan berkumpul dan juga mengikuti lomba-lomba. 2 . Solidaritas antara anggota sispala dengan ekstrakulikuler lain di sekolah, bentuk dari solidaritas yang terjadi adalah kegiatan tahunan anjangsana yang dilakukan bersama ekstrakulikuler PMR. 3. Solidaritas sosial antara sispala dengan organisasi pecinta alam lain, bentuk dari solidaritas sosial yang terjadi adalah Mapala Stipepa dan Mapala UMSB sebagai pemateri dalam kegiatan PDCA sispala. Solidaritas sosial dalam ekstrakulikuler Sispala Equator di SMA Pembangunan Laboratorium UNP muncul karena adanya rasa saling percaya dan pembagian kerja yang terjalin didalamnya.
\end{abstract}

Kata kunci: Solidaritassosial, Ekstrakulikuler, Sispala

Abstract

This study aims to see solidarity in extracurricular activities in high school sispala UNP Development Laboratory. The theory used in this research is the theory of social solidarity expressed by Emile Durkheim. The method used in this study is a qualitative approach with descriptive research type. Data obtained by observation, interview and documentation. Then the data obtained were analyzed using the technique of Miles and Huberman. The results of this study found the three forms of solidarity in extracurricular sispala, namely 1. Solidarity among members in extracurricular sispala, forms of social solidarity is a frequentgathering activities and also to follow the competitions. 2. Solidarity among members sispala with other extracurricular activities at school, forms of solidarity that happens is an annual event conducted jointly anjangsana extracurricular PMR. 3. Social solidarity between sispala with other nature lover organization, forms of social solidarity that happens is Mapala Stipepa and Mapala UMSB as speaker in sispala PDCA activities. Social solidarity in extracurricular activities in high school Sispala Equator UNP Development Laboratory arise because of the mutual trust and the division of labor that exists therein.

Keywords: Social solidarity, Extracurricular, Sispala

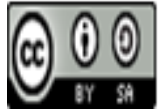




\section{Pendahuluan}

Setiap orang membutuhkan hubungan sosial dengan orang-orang lainnya, dan kebutuhan ini terpenuhi melalui pertukaran pesan yang berfungsi sebagai jembatan untuk mempersatukan manusia yang satu dengan yang lainnya (Afidah, 2014). Manusia sebagaimahluk sosial dalam rangkaian perjalanan hidupnya senantiasa berinteraksi dengan manusia lainnya sehingga dengan sendirinya manusia terlibat dalam kelompok (Putri, S. K., \& Hasanah, 2018). Gotong royong misalnya, pada dasarnya manusia sesuai dengan fitrahnya merupakan makhluk sosial yang tidak biasa hidup sendiri melainkan membutuhkan pertolongan orang lain (Irfan, 2017). Oleh karena itu kita disebut sebagai makhluk sosial. Karena dimanapun kita pasti membutuhkan orang lain. Lingkungan tempat tinggal, lingkungan maupun lingkungan yang baru ditemui, seperti sekolah. Sekolah mempertemukan anak-anak dengan orang yang tidak dikenalnya, sehingga anak dipaksa agar bisa berinteraksi dan membangun hubungan sosial dengan lingkungan sekolahnya. Schne iders (1964) menyebutkan penyesuaian sosial sebagai kemampuan individu untuk bereaksi secara efektif dan bermanfaat terhadap realitas sosial, situasi, dan hubungan sehingga tuntutan atau kebutuhan dalam kehidupan sosial terpenuhi dengan cara yang dapat diterima dan memuaskan. Dengan demikian, jika siswa ingin mengembangkan kemampuan dalam penyesuaian sosial di lingkungan sekolah maka ia harus menghargai hak orang lain, mampu menciptakan suatu relasi yang sehat dengan orang lain, mengembangkan persahabatan, berperan aktif dalam kegiatan sosial, menghargai nilai-nilai dari hukum-hukum sosial dan budaya yang ada di lingkungan sekolahnya (Maslihah, 2011).

Sekolah merupakan salah satu lembaga yang didirikan oleh pemerintah dalam rangka mencerdaskan kehidupan bangsa sebagaimana cita-cita dari Negara Indonesia yang tertuang dalam pembukaan Undang-Undang Dasar 1945. Jenjang pendidikan sekolah dimulai dari Sekolah Dasar (SD), Sekolah Menengah Pertama (SMP)/MTsN dan Sekolah Menengah Atas (SMA)/SMK/MA(Pemerintah Republik Indonesia, 2003). Setiap jenjang pendidikan memiliki prosedur dan kurikulumnya masing-masing. Perbedaannya disesuaikan dengan yang dikeluarkan oleh PemerintahPusat/ Kementerian Pendidikan dan Budaya. Sekolah juga menjadi tempat anak untuk melatih kepekaan sosial agar interaksi dilingkungannya menjadi baik (Kholik, 2017). Lingkungan Sekolah merupakan lingkungan yang meliputi semua hal yang berpengaruh dan bermakna bagi siswa dalam proses belajar mengajar yang ada disekolah, baik itu dalam lingkungan sosial (lingkungan fisik) maupun lingkungan nonsosial (lingkungan akademik) (Wahyuningsih \& Djazari, 2013). Selain untuk belajar, sekolah juga mempunyai fungsi lain yaitu sebagai tempat mengembangkan bakat dan minat siswa. Menurut Hilgar minat adalah suatu proses yang tetap untuk memperhatikan dan memfokuskan diri pada sesuatu yang diminatinya dengan perasaan senang dan rasa puas (Suharyat, 2009). Sedangkan bakat adalah kemampuan yang dimiliki oleh individu sejak lahir yang dipengaruhi oleh sifat bawaan orang tua yang masih perlu dilatih dan dikembangkan lagi (Irawan, 2011) Tujuansekolah untuk menumbuhkan minat dan bakat siswa direalisasikan dengan adanya Ekstrakulikuler.

Menurut Peraturan Menteri Pendidikan Dan Kebudayaan Republik Indonesia Nomor 62 Tahun 2014 Tentang Kegiatan Ekstrakurikuler ayat (2) yaitu, kegiatan Ekstrakurikuler diselenggarakan dengan tujuan untuk mengembangkan potensi, bakat, minat, kemampuan, kepribadian, kerjasama, dan kemandirian peserta didik secara optimal dalam rangka mendukung pencapaian tujuan pendidikan nasional.(Yanti, N., Adawiah, R., \& Matnuh, 2016) Ekstrakulikuler yang disediakan oleh pihak sekolah pun beragam, mulai dari kegiatan yang berada didalam kelas sampai kegiatan yang berada diluar kelas atau lapangan. Setiap 
sekolah memiliki ekstrakulikuler yang berbeda pula, tergantung dari kebijakan dan kebutuhan siswa dalam sekolah tersebut. Sispala merupakan salah satu ekstrakulikuler yang ada di SMA Pembangunan Laboratorium UNP. Ekstrakulikuler ini merupakan salah satu dari dua ekstrakulikuler yang pertama kali ada disekolah ini. Sispala Equator merupakan sebutan untuk sispala yang ada di SMA Pembangunan. Sispala ini lahir pada tahun 1997 dan didirikan oleh 10 orang perintis. Organisasi ini bertujuan untuk menciptkana anggota yang aktif dan tanggap terhadap alam dan lingkungan sekitar, serta ikut dalam melestarikan alam dan lingkungan. Sudah 22 tahun organisasi ini berdiri dan sudah mempunyai 20 angkatan. Bertahannya organisasi tentua da faktornya, yaitu salah satunya kekompakan dalam terus mengibarkan bendera Equator. Ini membuat sebuah rasa kepemilikan oleh anggota agar terus menerus bisa mengibarkan dan melanjutkan kegenerasi-generasi selanjutnya. Ini juga karena disusunnya struktur kepengurusan agar memudahkan setiap kegiatan sispala.

Salah satu keunikan dari organisasi ini adalah penggunaan bahasa yang bagi orang luar organisasi sebagai bahasa yang kurang sopan, seperti penggunaan kata-kata ang, kau dan bacaruiknya orang minang. Namun solidaritas yang terbangun didalamnya tetap tinggi dalam organisasi tersebut. Terbukti dengan banyaknya kegiatan yang dilakukan didalamnya, seperti agenda berkumpul mingguan, acara latihan gabungan dengan organisasi lain, angjangsana dan mengikuti event-event lomba. Artikel ini menjelaskan tentang solidaritas yang ada dalam organisasi Sispala Equator di SMA Pembangunan Laboratorium UNP.

\section{Metode Penelitian}

Penelitian ini melihat solidaritas dalam ekstrakulikuler sispala di SMA Pembangunan Laboratorium UNP. Dengan subjek penelitian anggota Sispala Equator, siswa/i SMA Pembangunan yang bukan anggota sispala, Pembina dan juga wakil kesiswaan. Dalam penelitian ini digunakan teknik pemilihan purposive sampling, yakni pemilihan informan dimana sudah ditentukan ciri-ciri khusus yang sesuai dengan tujuan penelitian (Sukardi, 2009). Disini dilakukan pemilihan informan yang sudah ditentukan karakteristiknya. Setelah ditentukan informan barulah melakukan wawancara dengan informan yang dipilih.

Dalam penelitian ini, setelah menentukan informan, barulah dilakukan observasi. Observasi yang digunakan adalah observasi partisipatif. Mengamati apa yang dikerjakan orang, mendengarkan apa yang diucapkan dan berpartisipasi dalam aktivitas yang diteliti (Emzir, 2010). Dalam penelitian ini saya ikut langsung dalam kegiatan-kegiatan yang dilakukan, seperti berkumpul dan juga kegiatan pelantikannya.

Setelah melakukan observasi, lanjutlah kewawancara. Wawancara yang digunakan adalah wawancara mendalam, Wawancara mendalam (in deph-interview) merupakan teknik pengumpulan data yang didasarkan pada percakapan secara intensif dengan menggunakan pedoman wawancara atau catatan yang berisikan pemikiran yang merupakan pertanyaan mendalam yang akan ditanyakan pada saat wawancara berlangsung (Sugiyono, 2016). Semua informan diberikan beberapa pertanyaan, dan semua pertanyaan yang diberikan sama. Lalu dikali lebih dalam informasi-informasi yang mereka ketahui sehingga tidak ada yang ditutupi.

Metode ini digunakan karena sesuai dengan penelitian yang saya lakukan. Dimana kegiatan yang dilakukan dalam penellitian ini ada diluar kelas dan banyak dilakukan di alam atau lingkungan. Wawancara dilakukan dengan cara wawancara mendalam agar hasil yang didapatkan bisa lebih deskriptif. Selain itu agar data lebih akurat, selain dari wawancara maka dilakukan observasi partisipatif, karena saya bisa melihat dengan langusng apakah data yang saya dapatkan dari wawancara sesuai dengan apa yang terjadi, karena itulah dalam penelitian ini saya menggunakan observasi partisipasi. Metode ini digunakan adalah dari miles dan 
Hubermen. Awalnya saya mengumpulkan data-data yang diperlukan dalam penenlitian, lalu setelahnya peneliti mereduksi data, mengelompokan data-data berdasarkan bentuk solidaritas sosialnya. Setelah data dikelompokan barulah disajikan data tersebut dalam bentuk kalimat dan foto. Langkah akhirnya adalah menarik kesimpulan dari data-data yang telah didapatkan.

\section{Hasil dan Pembahasan}

Salah satu temuan dari penelitian yang telah dilakukan sebelumnya yang berjudul solidaritas dalam ekstrakulikuler sispala di SMA Pembangunan Laboratorium UNP ditemukan bahwa adanya solidaritas sosial yang terjadi antara sesama anggota didalam organisasi tersebut. Dengan kosa kata dan bahasa yang digunakan kurang sopan, mereka masih bisa mempertahankan solidaritas yang ada didalamnya. Dengan adanya solidaritas tersebut, maka kesadaran akan hidup bersama - sama akan mencuat dan terasa oleh masyarakat tersebut (Arbi, F. R., \& Susilawati, 2019)

Solidaritas ini tercipta karena adanya rasa percaya dan juga pembagian kerja yang ada dalam organisasi tersebut. Didalam organisasi terdiri dari struktur mulai dari pembina, pelatih, DPH (Dewan Pengurus Harian) dan juga anggota. Masing-masing dari struktur tersebut mempunyai peran dan tanggungjawab. Kegiatan yang mereka ikuti antara lomba LLJJ, lomba Mountain Runnig, dan Gladian. Selain dari mengikuti kegiatan mereka juga sering berkumpul. Dalam semingu mereka punya jadwal berkumpul sebanyak 1 kali. Diluar dari agenda itu mereka juga sering berkumpul. Mereka bertemu di sekolah setiap hari, sehingga mereka menjadi lebih akrab satu sama lainnya. Itulah yang menjadikan mereka makin solid dan juga saling percaya satu sama lainnya. Karena mereka sudah menanggap teman satu organisasinya sebagai keluarga.Bentuk dari pembagian kerja yang mereka lakukan adalah pembagian tugas dri masing-masing kepengurusan. DPH bertugas untuk menyusun agenda kegiatan satu tahun kedepannya, pembina mendampingi mereka dalam proses pengurusan izin kegiatan ke pihak sekolah, dan anggota menjalankan kegiatan yang telah disusun tersebut.

Selain dari adanya solidaritas antara sesama anggota, ditemukan juga hasil bahwa ada solidaritas yang terjalin antara anggota sispala dengan anggota ekstakulikuler lain, juga antara sispala dengan organisasi pecinta alam lainnya. Ini dibuktikan dengan adanya kerjasama yang terbangun antara sispala baik itu dengan ekstrakulikuler PMR, basket, dan juga dengan organisasi kepecinta alaman lainnya seperti Mapala Stipepa dan Mapala UMSB. Bentuk solidartitas yang terjalin antara sispala dengan ekstrakulikuler lain adalah kegiatan tahunan anjangsana yang selalu bekerjasama dengan PMR. Solidaritas yang terbangun antara sispala dengan organisasi pecinta alam lain ialah kegiatan gabungan yang dilakukan setiap sekali seminggu bersama Mapala Stipepa, dan juga Mapala UMSB sebagai pemateri dalam kegiatan PDCA sispala.

Temuan dalam artikel ini dianalisis dengan teori solidaritas sosial yang dikemukakan oleh Emile Durkheim. Durkheim yang mengatakan bahwa solidaritas merupakan perasaan saling percaya antara para anggota dalam suatu kelompok atau komunitas. Kalau orang saling percaya maka mereka akan menjadi satu/menjadi persahabatan, menjadi saling hormat menghormati, menjadi terdorong untuk bertanggung jawab dan memperhatikan kepentingan sesamanya. Solidaritas sosial dalam pandangan Durkheim adalah orang-orang dipersatukan oleh spesialisasi dan kebutuhan untuk layanan-layanan dari orang lain (Saifullah, 2015). Dalam karyanya yang berjudul The Devision of Labour in Societypadatahun 1964, Durkheim juga mengatakan bahwa pertumbuhan dalam pembagian kerja meningkatkan suatu perubahan dalam struktur sosialdaritas sosial smekanik ke solidaritas organik.(Santoso, S., \& Harsono, 2014). 
Penelitian ini sebagai salah satu kajian dimana kekompakan dan solidaritas juga bisa terbangun didalam sebuah organisasi yang penggunaan bahasanya kurang sopan. Ini dilandaskan pada konsep dari solidaritas itu sendiri, bahwasanya solidaritas itu muncul karena adanya rasa percaya dan pengembangannya adalah adanya pembagian kerja yang menyebabkan satu sama lain saling bergantung. Penelitian ini juga membuktikan bahwa ada solidaritas yang tinggi didalam ekstrakulikuler sispala yang terbangun antara sesame anggota didalam organisasi sispala di SMA Pembangunan Laboratorium UNP.

\section{Kesimpulan}

Solidaritas sosial merupakan sebuah rasa sailing percaya, dan pengembangannya adalah adanya pembagian kerja yang terjadi sehingga menciptakan sebuah ketergantungan antara satu dengan lainnya. Cara berbahasa yang unik dari Sispala Equator, yaitu menggunakan bahasa yang menurut orang yang berada diluar organisasi adalah kata-kata yang kurang sopan tidak menjadi halangan terciptanya sebuah solidaritas sosial, bahkan solidaritas yang ada bisa dikatakan tinggi karena seringnya kegiatan yang merekalakukan. Hal ini yang membuktikan bahwa solidaritas sosial dalam ekstrakulikuler sispala di SMA Pembangunan Laboratorium UNP tinggi.

\section{Daftar Pustaka}

Afidah, N. (2014). Komunikasi Organisasi Karang Taruna Dalam Membangun Solidaritas Antar Anggota: Studi Kasus Karang Taruna Setya Bhakti, Ds. Pagerwojo, Kec. Buduran, Kab. Sidoarjo. Doctoral Dissertation, UIN Sunan Ampel Surabaya.

Arbi, F. R., \& Susilawati, N. (2019). the consequences that arise after the conflict between online ojek and conventional ojek at air tawar barat. Jurnal Perspektif, 2(3), 316-326.

Emzir. (2010). Metodologi Penelitian Kualitatif Analisis Data. Jakarta: Rajawali Pers.

Irawan, S. (2011). Pengembangan bakat kepemimpinan siswa melalui kegiatan OSIS di SMA N 4 Depok. Retrieved from repository.uinjkt.ac.id

Irfan, M. (2017). Metamorfosis Gotong Royong Dalam Pandangan Konstruksi Sosial. Prosiding Penelitian Dan Pengabdian Kepada Masyarakat, 4(1), 1-10.

Kholik, N. (2017). Peranan sekolah sebagai lembaga pengembangan pendidikan multikultural. Jurnal Tawadhu, 1(2), 244-271.

Maslihah, S. (2011). Studi tentang hubungan dukungan sosial, penyesuaian sosial di lingkungan sekolah dan prestasi akademik siswa SMPIT Assyfa Boarding School Subang Jawa Barat. Jurnal Psikologi Undip, 10(2), 103-114.

Pemerintah Republik Indonesia. Undang-undang Republik Indonesia nomor 20 tahun 2003 tentang sistem pendidikan nasional. , (2003).

Putri, S. K., \& Hasanah, N. (2018). Solidaritas Sosial Anggota Organisasi Bsa Owner Motorcycle'siantar (Bom's) Di Kota Pematangsiantar. Socius, 5(1), 32-41.

Saifullah, S. (2015). Solidaritas Sosial Buruh Nelayan Dalam Meningkatkan Perekonomian Masyarakat Desa Beluk-Kenek Kecamatan Ambunten Kabupaten Sumenep. Disertasi. UIN Sunan Ampel Surabaya.

Santoso, S., \& Harsono, J. (2014). Pola Solidaritas Kelompok Pedagang Angkringan di Kota Ponorogo. Sosiohumaniora, 16(1), 87-96.

Sugiyono. (2016). Metode Penelitian Kombinasi. Bandung: Alfabeta.

Suharyat, Y. (2009). Hubungan antara sikap, minat dan perilaku manusia. Jurnal Region, $1(3), 1-19$. 
Sukardi. (2009). Metodologi Penelitian Pendidikan. Jakarta: Bumi Aksara.

Wahyuningsih, S., \& Djazari, M. (2013). Pengaruh Lingkungan Sekolah dan Kebiasaan Belajar Terhadap Prestasi Belajar Akuntansi Siswa Kelas XI IPS SMA Megeri 1 Srandakan. Kajian Pendidikan \& Akuntansi Indonesia, 2(1), 137-160. https://doi.org/http://download.portalgaruda.org/article.php

Yanti, N., Adawiah, R., \& Matnuh, H. (2016). Pelaksanaan kegiatan ekstrakurikuler dalam rangka pengembangan nilai-nilai karakter siswa untuk menjadi warga negara yang baik di sma korpri banjarmasin. Jurnal Pendidikan Kewarganegaraan, 6(11), 1-8. 